\title{
DOE/PC/90177-- T/2
}

\section{EVALUATION, ENGINEERING AND DEVELOPMENT OF ADVANCED CYCLONE PROCESSES}

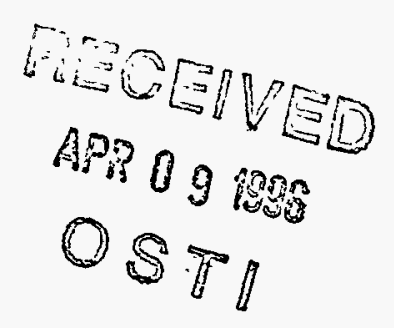

QUARTERLY TECHNICAL PROGRESS REPORT

Quarterly Report \#15

For The Period April 1, 1994 to June 30, 1994

Work Performed Under DOE Contract \# DE-AC22-90PC90177

For

U.S. Department of Energy

Office of Fossil Energy

Pittsburgh Energy Technology Center

P.O. Box 10940

Pittsburgh, Pennsylvania 15236

By

Coal Technology Corporation

103 Thomas Road

Bristol, Virginia 24201

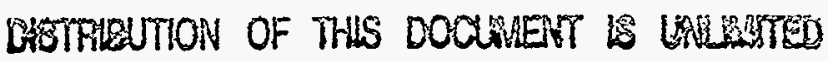




\section{DISCLAIMER}

This report was prepared as an account of work sponsored by an agency of the United States Government. Neither the United States Government nor any agency thereof, or any of their employees, makes any warranty, express or implied, or assumes any legal liability or responsibility for the accuracy, completeness, or usefulness of any information, apparatus, product or process disclosed, or represents that its use would not infringe privately-owned rights. Reference herein to any specific commercial product, process, or service by tradename, trademark, manufacturer, or otherwise, does not constitute or imply its endorsement, recommendation, or favoring by the United States Government or any agency thereof. The views and opinions of the authors expressed herein do not necessarily state or reflect those of the United States Government or any agency thereof. 


\section{EXECUTIVE SUMMARY}

The project goal is to develop an advanced coal beneficiation technology that can achieve high recovery of the parent coal's calorific value, while maximizing pyritic sulfur removal. Coal cleaning is to be accomplished by physical means incorporating an advanced form of cycloning or gravimetric process. Evaluation of different media types and their attendant systems for recovery, concentration, and regeneration is to be completed.

Phase I, Media Evaluation, now completed, involved a paper study and a number of laboratory tests to eliminate all but the best media options. Phase II, Media Testing, involved detailed testing of the more promising media and separators in a closedloop pilot facility circuit.

In the final phase, Phase III, it is proposed to test individual components of the process using the optimum medium, separator, and medium recovery system(s) selected in prior phases.

Major activities and developments that occurred during this reporting period are reviewed below.

A manuscript and visual material were prepared and submitted for the annual Contractors Conference.

Revised Work, Cost, and Labor Plan drafts were sent on April 5, 1994.

The Work Plan was revised and submitted again in draft form on May 19, 1994. Corresponding Cost and Labor plans were not submitted at this time. Test matrices, detailing the filter and decanter test program, were included in this rendering of the proposed Work Plan.

Outomec conducted a second set of hot water wash experiments on April 21, 1994. These hot water experiments, using prefiltered medium, yielded a significant improvement in calcium nitrate recovery, and showed a consistent decrease in residuum calcium nitrate with increasing wash rate.

Several alternatives were investigated for potential reduction in thermal regeneration process costs. Culligan, SpinTek, and Rochem, manufacturers of reverse osmosis or ultra filtration systems were contacted. Rochem ultimately performed laboratory experiments. Starting with a dilute medium density of 1.07 , the Rochem laboratory system achieved a density of 1.11 . A density of $1.22 \mathrm{sg}$ would be commercially attainable. This is less than the target medium density of 1.35 , meaning that if their system were utilized, some thermal means would still be required to regenerate medium to operating density. 
The third draft of the Final Separating and Media Evaluation Report (FSMER) was prepared and submitted on May 27, 1994. It was returned because of disagreement with figures shown in Table 5, comparing the relative costs of the calcium nitrate and organic processes.

Management and Technical Systems initiated work on a preliminary economic study and will submit a report during the next Quarterly reporting period.

PTI closed their facility in Calumet, MI and established an office in Lexington, KY. Mel Laurilla is now the prime contact for sample collection, analytical work, assistance during the test program, assistance in preparing reports, and other remaining PTI responsibilities. 


\section{INTRODUCTION}

"Evaluation, Engineering and Development of Advanced Cyclone Processes" is a research and development project aimed at reducing pyritic sulfur in coal products. Minimum project goals are to produce a $6 \%$ product ash and $85 \%$ pyritic sulfur rejection while retaining $85 \%$ of the parent coal's heating value. A number of media and separator options are to be evaluated and tested, and performance characteristics of critical components investigated in a $1,000 \mathrm{lb} / \mathrm{hr}$ closed loop test stand constructed on a site provided by Coal Technology Corporation (CTC) in Bristol, Virginia.

The project involves the physical beneficiation of coal based on the density differential that exists between clean coal and its impurities, i.e., pyrite and ash bearing minerals. Coal may be beneficiated by employing a parting liquid or pseudo-liquid with a specific gravity between that of coal and its impurities. A number of parting liquids (separating media) were considered for evaluation and testing in this program. They represented three families of liquids: aqueous solutions, organic liquids, and aqueous suspensions. The aqueous suspensions of starch and solutions of sugar, though environmentally benign, were dropped from consideration early in the program because of their high viscosity and handling difficulties. Micronized magnetite, an aqueous suspension, was also dropped because another firm plans to develop it to commercialization.

Except for the aqueous suspensions, the candidate media may be classified as true heavy liquids. True heavy liquids are not affected by the multiple gravities (g) required in fine coal gravimetric separation processes, whereas suspensions may deteriorate if subjected to excessive $\mathrm{g}$ force. Multiple gravities in combination with true heavy liquids can be used to increase the speed and efficiency of separation of particles of small size having slight differences in density. Generally, the greater the number of gravities the more precise the separation. This implies the use of small diameter, high-pressure cyclones or high gravity centrifuges. Therefore, the term cycloning encompasses centrifuges and other enhanced-gravity devices where fluid motion or mechanical motion is converted to centrifugal force.

\section{Task 1 - Project Planning and Management}

Task Description or Objective(s): The objective of this task is good technical and fiscal control and management of this project, both internally and externally, by Coal Technology Corporation (CTC), the prime contractor. CTC is responsible for interfacing with the DOE and ensuring that all subcontractors fulfill their responsibilities and meet the milestones and goals of the Project Work Plan. The subcontractors are: 
- Process Technology, Inc. (PTI) - providing analytical services and conducting Phases I and II laboratory and closed-loop media testing.

- ICF Kaiser Engineers, Inc. (ICF-KE) - performing detailed design of a 1000 $\mathrm{lb} / \mathrm{hr}$ Bench Scale Circuit.

- Intermagnetics General Corporation (IGC) - providing media, separator, and technical service for magnetically enhanced media.

Project management is an ongoing effort designed to monitor the subcontractors, keep the project running smoothly, resolve problems, and in general ensure that the project is performed on a timely and cost effective basis.

Activity: Due to the limited funds remaining in the project budget, it was decided to undertake component testing rather than the construction and testing of a complete integrated circuit as originally planned. Critical components include size reduction, separation, and filtering systems. It is also proposed that evaporative studies investigating $\mathrm{pH}$ variation, corrosion potential, and medium condition be performed by a qualified vendor. Several revisions of the Work Plan were developed during this reporting period, with work concentrating on defining the test matrices to be utilized in component testing and defining the costs to perform them. Approval of the revised Work Plan is pending.

\section{Task 2 - Coal Procurement and Characterization (Three Phases)}

Task Description or Objective(s): The objective of this task is to provide characterized feedstock for all three phases of the program. The three phases are associated with: (I) Separating Media Evaluation, (II) Separating Media Testing, and (III) Process Optimization Testing. A total of four coals have been selected for the program. The four coals constitute a substantial reserve, are technically difficult to clean, and contain significant amounts of pyritic sulfur. The characterization will determine the degree of liberation needed to reach the project goals. This information will be used as a database for the entire program and to measure the performance of individual tests.

The project's requirements for the four coals include:

- Raw coals must have moderate to high pyritic sulfur contents that are not sufficiently liberated by conventional cleaning.

- Precleaning operations must recover 90 to $95 \%$ of the parent raw coal's heating value while principally removing coarse rock and fine clays. 
- Raw and clean coal handling systems must facilitate readily obtaining one-totwo ton samples of the raw and precleaned coals for Phase I and III characterization

Activity: No activity during this period.

\section{Task 3 - Evaluation Plan and Test Plan Formulation}

Task Description or Objective(s): Task 3 represents the planning stage of the work that will be conducted during Phases I through III of Task 6 . It is the technical basis of the program and provides for evaluating the media by paper study supplemented by laboratory study, selection of medium and separator combination, and implementation of one medium/separator option for long-term, open loop testing. The three phases of this task are:

$\begin{array}{lll}\text { - Phase I } & \text { Media Evaluation } \\ \text { - Phase II } & \text { Separating Media Testing } \\ \text { - Phase III } & \text { Process Optimization Testing }\end{array}$

These plans detail Task 6, Scope of Work.

Activity: The Separating Media Evaluation Plan was approved by DOE in February, 1991. The Preliminary Separating Media Evaluation Report contains the Separating Media Test Plan, which was carried out during Phase II. A draft Process Optimization Test Plan for Phase III was submitted on December 18, 1992, intended as a plan for an integrated circuit. The pending Work Plan would require a Component Test Plan instead.

\section{Task 4 - Bench Scale Test Circuit Design}

Task Description or Objective(s): This completed task provided the design of a fully integrated bench scale advanced cycloning test circuit (BSC). The design of the advanced cycloning test circuit was based on the Separating Media Evaluation and Testing results (Phases I and II) and the detailed characterization of the four proposed test coals. ICF-KE was the lead team member for Task 4.

The BSC design fully integrates all pretreatment, cleaning, and post-cleaning operations necessary to allow continuous steady-state operation including at least one (1) uninterrupted run of 100 hours duration for each of the four test coals. 
Activity: No activity during this period. The revised Work Plan suggests that the bottom portion of the BSC design be used in erecting a smaller facility designated as a Component Test Stand (CTS).

\section{Task 5 - Bench Scale Test Circuit Set-Up and Commissioning}

Task Description or Objective(s): This task covers the functions necessary to construct and commission the bench scale circuit module at CTC in Bristol, Virginia. The construction will be performed by an experienced contractor with construction management provided by CTC. The start-up will be supervised by CTC and performed by craft labor supplied by the construction contractor.

Activity: This activity is on hold pending approval of the revised Work Plan. The Work Plan under consideration proposes construction of a Component Test Stand (CTS) utilizing the bottom portion of the BSC, as designed.

\section{Task 6 - Evaluation and Test Plan Implementation}

Task Description or Objective(s): This task consists of the technical implementation of plans produced and approved under Task 3. Please refer to the project Separating Media Evaluation Plan and Separating Media Test Plan.

\section{Phase I - Media Evaluation}

Activity: The media evaluation has been completed and reported in the revised Preliminary Separating Media Evaluation Report (PSMER) during a prior reporting period. In the PSMER, methylene chloride/perchloroethylene, calcium nitrate/water, MEM (Magnetically Enhanced Media) and water were selected as media for inclusion in the test matrix for performance testing during Phase II.

\section{Phase II - Separating Media Testing}

Activity: During Phase II calcium nitrate was selected as the preferred medium as reported in the Final Separating Media Evaluation and Test Report (FSMER). Due to economic concerns associated with the calcium nitrate-based process circuit, thinking continued during this reporting period on methods to lower process costs. One method under consideration is to improve medium recovery via a hot water rinse. Initial filtering and cake washing tests were conducted with cold water. Outomec, vendor for the selected dewatering technology, performed the first hot water wash filtering tests during the last quarterly reporting period, but failed to achieve significant gains in calcium nitrate recovery. 
Outomec conducted a second set of hot water wash experiments on April 21, 1994. During this second group of experiments, prefiltered medium was utilized, whereas the first hot water tests, conducted in February 1994, used fresh, unfiltered medium. The more recent experiments showed a consistent decrease in residual calcium nitrate with increasing wash rate for both clean coal and refuse; however, significant improvement in calcium nitrate recovery from refuse was seen only at wash rates previously considered uneconomic (see FSMER, Table 3). These results are shown in Table 1 and Figures $1 \mathrm{~A}$ and $1 \mathrm{~B}$ in comparison with initial hot water results as well as results from 1992 when a cold water rinse was utilized. The cold water experiments utilized prefiltered medium solutions. It is believed that prefiltering of the medium improves filtering efficiency and thereby rinsing performance by removing trace contaminants that block the filter surface.

Several systems were investigated as alternatives to thermally regenerating medium. These alternative systems were considered to have potential for reducing overall process costs. Culligan, who markets a reverse osmosis system, was contacted, but was unresponsive after learning the circuit requirements. SpinTek, who markets a centrifugal membrane system, expressed interest and requested a sample of the dilute medium for study. However, achieving the process s.g. specification was beyond the capabilities of SpinTek who then suggested that Rochem be contacted. Rochem manufactures and markets a high pressure reverse osmosis system.

CTC requested that Rochem perform laboratory experiments to determine suitability, capacity, and performance of their system when concentrating dilute calcium nitrate solutions. Rochem tested the sample solutions on June 27, 1994 and reported the results on July 14, 1994. Starting with a dilute medium density of $1.07 \mathrm{sg}$ Rochem's 
Table 1

RESIDUAL CALCIUM NITRATE MEASUREMENTS OF WASHED FILTER CAKES

Outomec Cold Water Wash, 1992

Clean Coal

$\underline{\text { Reject }}$

\begin{tabular}{ll}
$\begin{array}{l}\text { Wash } \\
\text { Rate* }\end{array}$ & $\begin{array}{l}\text { \% Soluble } \\
\text { Calcium }\end{array}$ \\
\hline 1.24 & 0.748 \\
2.07 & 0.174 \\
2.13 & 0.177 \\
2.29 & 0.205 \\
2.80 & 0.369 \\
& \\
Wash & \% Soluble \\
Rate* & Calcium \\
0.00 & 3.838 \\
0.36 & 3.024 \\
0.42 & 3.143 \\
1.41 & 0.881 \\
1.37 & 1.312 \\
1.32 & 1.296
\end{tabular}

*Wash Rate $=$ wash water weight/dry solids weight.

Eimco Cold Water Wash, 1992

Clean Coal

$\underline{\text { Reject }}$
\% Soluble

Calcium

5.620

0.981

0.685

0.619

0.412

0.365

$\%$ Soluble

Calcium

5.230

0.903

0.621

0.520

0.467

0.458 
Table 1 (Continued)

Outomec Hot Water Wash, February 23-24, 1994

\begin{tabular}{cll} 
Clean Coal & $\begin{array}{l}\text { Wash } \\
\text { Rate* }\end{array}$ & $\begin{array}{l}\text { \% Soluble } \\
\text { Calcium }\end{array}$ \\
\hline 3.05 & 0.18 \\
3.99 & 0.17 \\
4.20 & 0.15 \\
3.37 & 0.17 \\
3.04 & 0.19 \\
3.62 & 0.17 \\
& 2.58 & 0.22 \\
& 3.55 & 0.15 \\
3.10 & 0.18 \\
& 2.58 & 0.22 \\
& 3.54 & 0.18 \\
& & \\
Reject & Wash & $\%$ Soluble \\
& Rate* & Calcium \\
& 4.55 & 0.74 \\
3.48 & 0.77 \\
3.07 & 0.64 \\
3.36 & 0.81 \\
& 2.95 & 0.80 \\
3.27 & 0.76 \\
3.31 & 0.78 \\
2.76 & 0.80
\end{tabular}

Outomec Hot Water Wash, April 21, 1994

Clean Coal

Wash

Rate*

1.40

1.80

2.57

$\%$ Soluble

Calcium

1.10

0.20

0.12

$\underline{\text { Reject }}$

Wash

Rate*

2.00

$\%$ Soluble

Calcium

0.89

3.60

0.14

0.13 


\section{FIGURE 1A. CLEAN COAL WASHING}

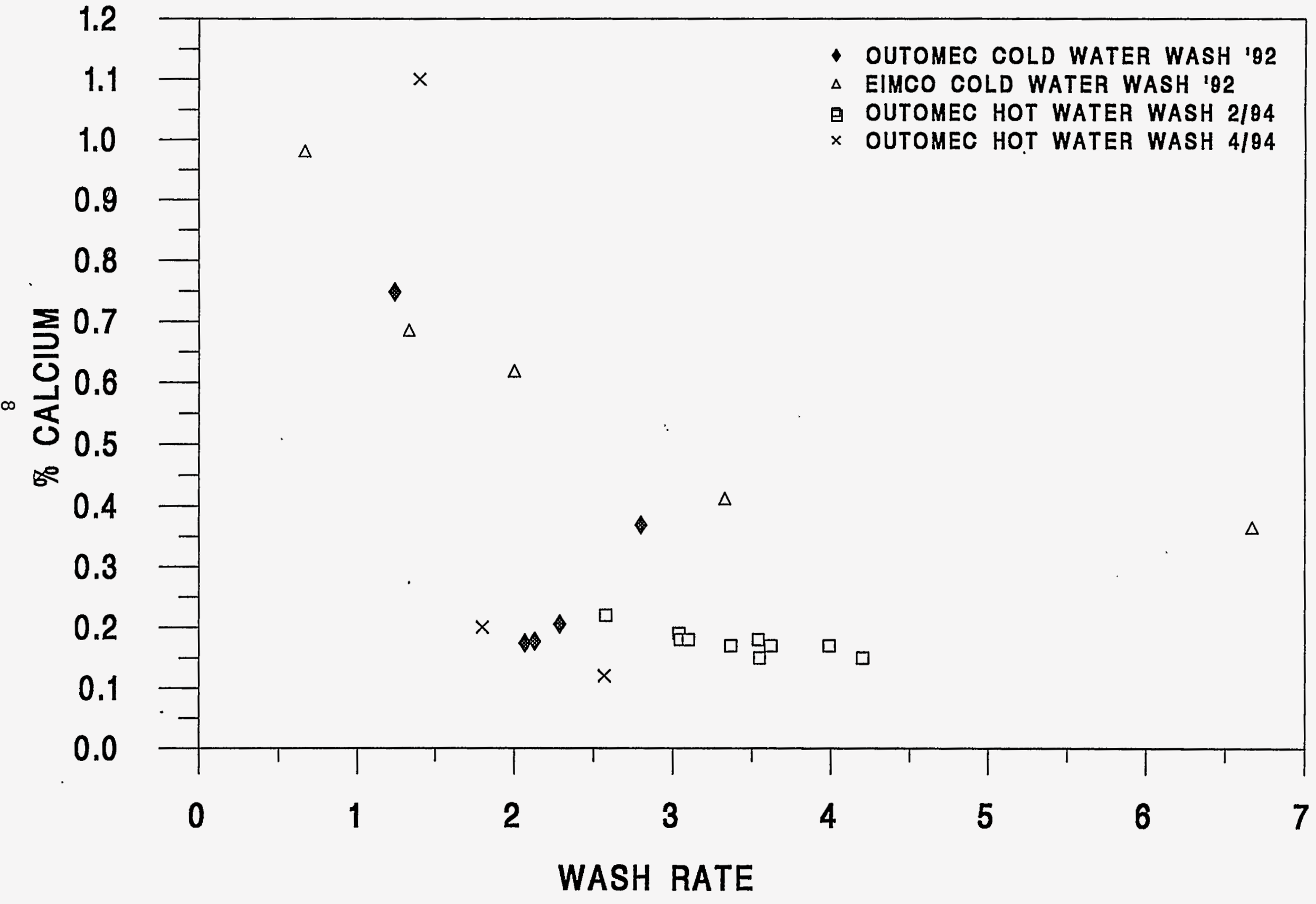




\section{FIGURE 1B. REFUSE WASHING}

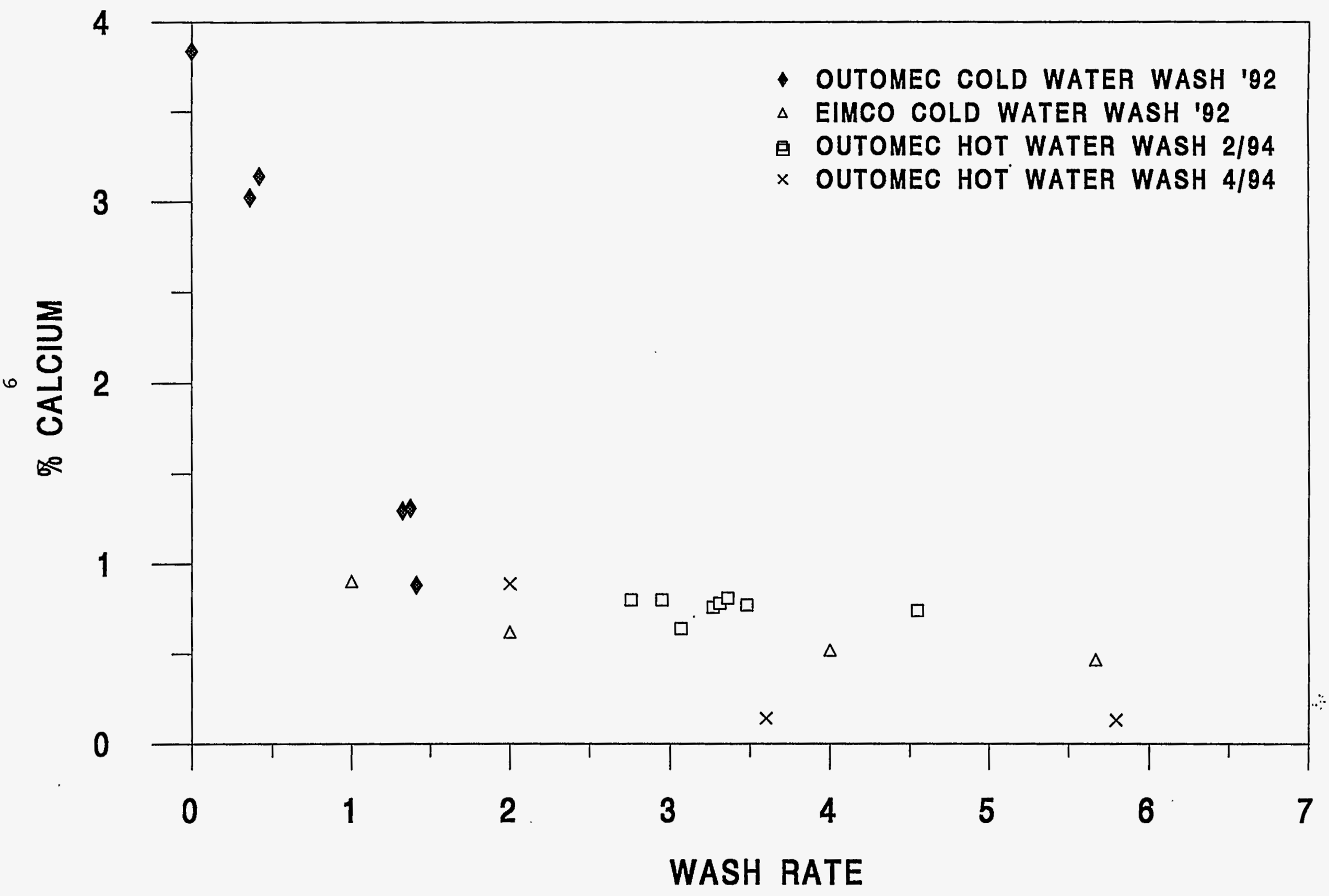


laboratory system, operating at $1400 \mathrm{psi}$, achieved a density of $1.11 \mathrm{sg}$. They advise that a commercial unit, operating at 3000 psi, could achieve a $36 \%$ salt concentration, which is equivalent to $1.22 \mathrm{sg}$. This is less than the target medium density of 1.35 , meaning that if their system were utilized, a thermal stage would still be required. Rochem's report is attached as Appendix A.

\section{Phase III - Process Optimization Testing}

Activity: It is proposed that component testing replace Process Optimization Testing.

\section{Task 7 - Data Analysis and Reporting}

Task Description or Objective(s): This task takes place throughout the project to keep up with the day-to-day logging of data and reporting requirements. Dissemination of data to the Project Team members is vital to the project. Analysis and interpretation of the data are critical to this task. Numerous reports are required during the life of the project. Technical reports required under the contract include the following: Biweekly and Quarterly Progress/Status Reports, Washability Analyses Report, Preliminary Separating Media Evaluation Report, Final Separating Media Evaluation and Test Report, and the Final Report.

Activity: The Biweekly and Quarterly reports have kept DOE informed concerning the progress of the project. Other reports and plans are covered under their applicable Tasks.

Information was compiled and provided to Management and Technical Systems for a report on the preliminary economics of the calcium nitrate process. Provided were: residuum results, wash rates, costs of chemical, and flowsheet circuitry.

\section{Task 8 - Conceptual Design}

Task Description or Objective(s): This task is performed with the objective of providing DOE with a conceptual description and detailed estimate of the cost to construct and operate a 20 tph advanced cycloning test module. This is a modification to the contract, which originally called for detailed design of a 3 tph circuit. CTC will be the lead team member for Task 8 . This Task involves the conceptual design of a fully integrated, continuous operation, advanced cycloning test module. The conceptual design will be sized for $20 \mathrm{tph}$ feed rate and will include all necessary pre-treatment, cleaning and post-treatment unit operations. The conceptual design will be based on the results of the Process Optimization Tests performed under Phase III of Task 6.

Activity: No activity during this period. 


\section{Task 9 - Final Reporting}

Task Description or Objective(s): The Project Team members will submit a Draft Final Technical Report in the 41st month of the project. This report will be preceded by a detailed outline to be reviewed by the DOE. The final report will meet contract requirements as stated in the Project Work Plan and will comply with DOE Order 1332.1A (Uniform Reporting System).

Activity: No activity during this period.

\section{Task 10 - Decommissioning}

Task Description or Objective(s): CTC shall be responsible for decommissioning, protecting, removing, and disposing of all contractor installed property encompassed by the contract. Contractor procured Government property shall be protected and dispositioned as directed by the DOE Contract Officer. This is strictly limited to the cost of decommissioning, removal, protection, and shipment from CTC to PETC.

Activity: No activity during this period. 
APPENDIX A 
Rochem Separation Systems 3904 Del Amo Boulevard Suite 801

Torrance, California 90503

Tel: (310) $370-3160$

Fax: $(310)$ 370-4988

July 14, 1994

Mr. Ted Durney

Coal Technology Corporation

103 Thomas Road

Bristol, VA 24201

Dear Mr. Durney;

Thank you for your interest in the Rochem Disc TubeTM technology. The sample of calcium nitrate submitted was processed in a high pressure bench scale test unit. The system diagram is shown in Figure 1. Due to the pressures involved the desired concentrate was not achieved, but the data from the lower concentrations was analyzed to determine the system requirements for your application.

As expected, the major concern in the the process was the high osmotic pressure associated with the concentration of calcium nitrate. The bench unit's operating capabilities allow a maximum operating pressure of $1500 \mathrm{psi}$. Therefore, it was necessary to operate the unit with the "light" solution. This consisted of 2.43 \# of calcium nitrate and 13.77 \# of water. The specific gravity of this solution is 1.1. Due to the water in the system before testing, the actual specific gravity was 1.07.

Based on the data collected for the system operating at $1400 \mathrm{psi}$, the experimental osmotic pressure was greater than theoretical. In order to process the sample to a specific gravity of 1.35 , it would take a system with an operating pressure in the 3500-4000 psi range. Unfortunately, this exceeds our capabilities at this time.

The alternative which we could provide would be a 3000 psi system which would allow you to achieve a concentration of approximately $36 \%$, after which thermal processes would be necessary to increase the concentration to $46 \%$. In pursuing this alternative we would recommend a second bench test at 3000 psi. Based on the results of this test, we would be prepared to adequately size a system to meet your specifications. 

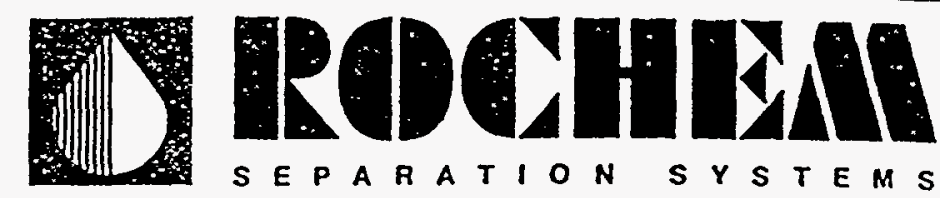

If you would like to pursue this venture we would be happy to discuss it with you. Thank you for your interest in Rochem and If you have any questions, please contact David LaMonica at (310) 370-3160.

Sincerely,

Rabel Calemen.

Ralph Valencia

Rochem Separation Systems, Inc. 

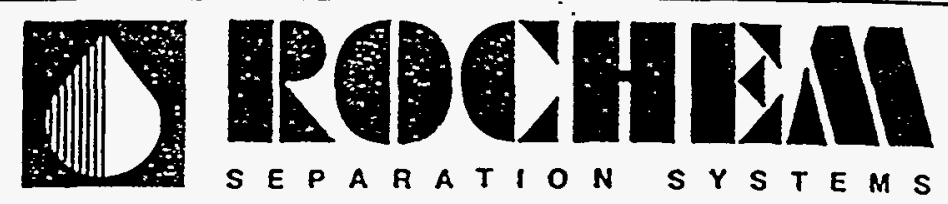

Operating Pressure - 1400 psi

Initial flux rate $-16.3 \mathrm{gfd}$

final flux rate $-5.0 \mathrm{gfd}$

\begin{tabular}{|l|c|cc|}
\hline Parameter & Initial Feed & Final Concentrate & Average Permeate \\
\hline conductivity $(\mathrm{mS} / \mathrm{cm})$ & 85.9 & 99.2 & 14.67 \\
\hline specific gravity & 1.07 & 1.11 & 1.00 \\
\hline
\end{tabular}




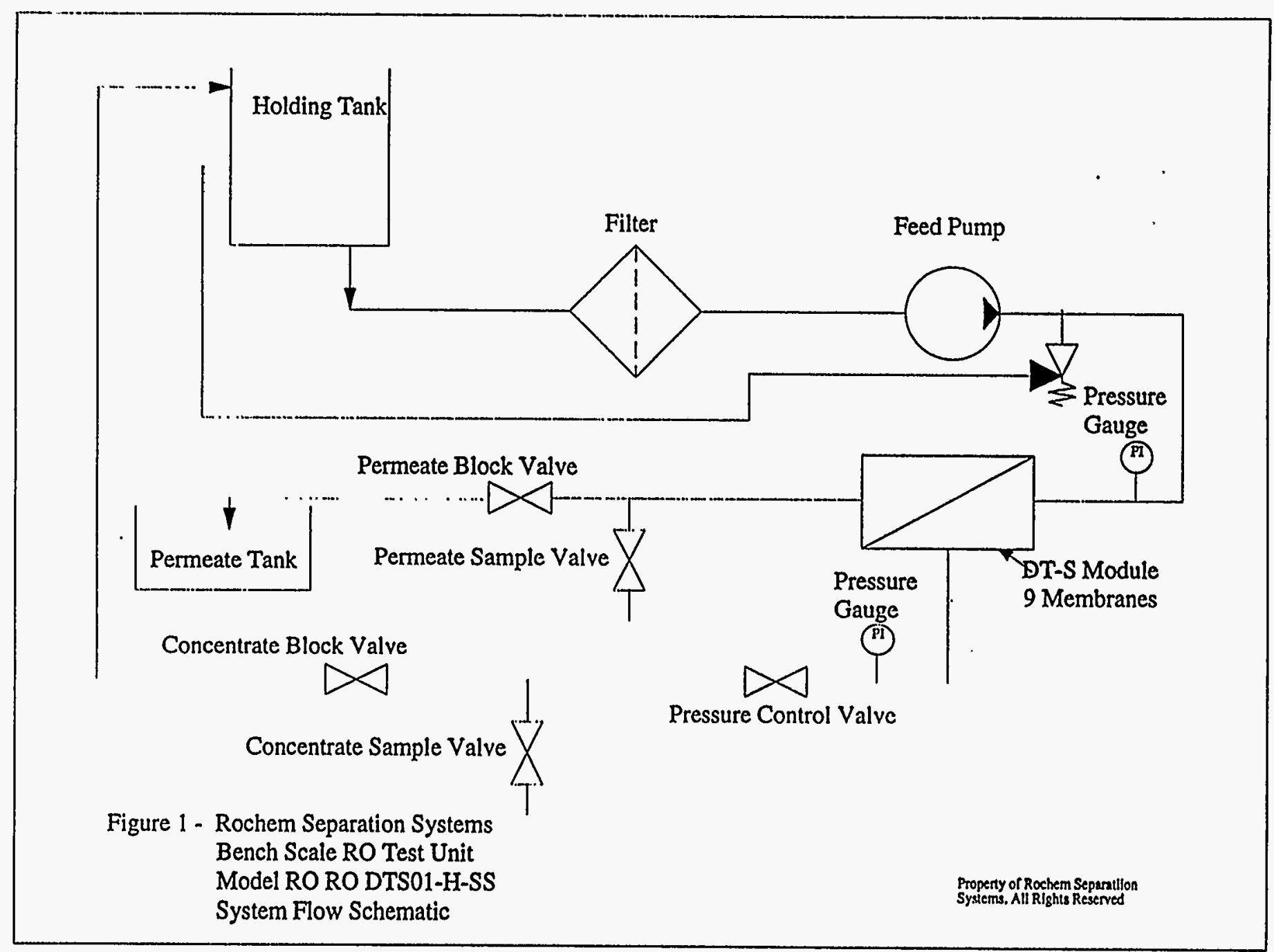

